\title{
An Experimental Study of Temperature Effect on Joint Cable Resistance
}

\author{
Sahar R. Al-Sakini, Athraa S. Hasan and Hadia K. Judran \\ Deptartment of Electromechanical Engineering, University of Technology, Ultimo, Australia
}

\begin{abstract}
A cable joints usually are used to connect, high, medium and low voltage cables. The type for joint cable, lengths, shapes, materials different according to the number of cores, voltage and insulation of cable to be jointed. So, in this study the effect of sleeve length, pollution, humidity and the temperature on the performance of the cable joint is presented. Splicing cable in this study done by using conventional method by using a hydraulic press to form a joint. The dissipation factor $(\tan \delta)$ and index dielectric losses are carried out for joint cables at different length sleeve to give an idea for a good cable insulation conditions and at different current between $(10-90 \mathrm{~A})$ with current steps of $(20 \mathrm{~A})$. The results test showed that the temperature for the joint cable significantly affect ed the dissipation factor $(\tan \delta)$ and index dielectric losses.
\end{abstract}

Key words: Joint, contact resistance, sleeve, dissipation factor, $\tan \delta$, index, losses connector

\section{INTRODUCTION}

The underground cable for transmission and distribution operates at maximum electrical current as possible. In power system, the underground cable represent a critical role. Any fault in electrical cable insulation causes a damage in the power system which causes un economic losses. Sever short/long term conditions service like a short circuit and over current could affect thermally in insulation cable and may be causes early aged (Sarathi et al., 2003).

In general, the connectors are the weak link in the electrical system which raises many questions about the ability of connectors designs to equip an effective connections. Most of connectors in service are subjected to outdoor environments. So, corrosion are recognized which signification reliability interest (Braunovic, 1994).

There are many factors affected on life time and the performance of electrical joint like joint length, humidity and pollution. The temperature and dissipation factor in high voltage equipments were discussed at many studies. Wang et al. (2009) they examined the effects of environment like humidity and temperature on tangent delta measurement at captive equipments. Otowski et al. (1993) introduced the time effected and temperature on dielectric dissipation factor for cable junction. Zhang and Wen (1986) investigated the contamination by dust which formed on the contact surface whose one of the main causes failure on electric system.

\section{MATERIALS AND METHODS}

Tan delta (Tan 8): When a pure insulator is connected across the Earth and line, it behaves like capacitor. At ideal insulators, the materials for insulating which acts as a dielectric are $100 \%$ pure, electric current passes through an insulator have only capacitive. At pure capacitance, the capacitive of electric current leads the voltage applied by $90^{\circ}$. There is no component resistive of the current which following from the line to ground through the insulators like ideal insulating materials.

In practice, the insulator materiel cannot made by $100 \%$, pure because of the impurities like moisture and dirt (mud and dust) enter. These dirtiness (mud and dust) provide the path of conductive for the current, consequently, electric leakage current passing from the line to ground through the insulator has a resistive component. So, for a good insulator, the component resistive for electric leakage current is quite low. Therefore, the ratio of resistive component to component capacitive must be determine to find a healthiness electrical insulator, this ratio for a good insulators would below. This ratio referred to $\tan$ delta $(\tan \delta)$ known as which signifies the losses where angle $(\delta)$ is the losses angle as shows in Fig. 1 (Werelius et al., 2012):

$$
\tan \delta=I_{R} / I_{c}
$$

Where:

$\mathrm{I}_{\mathrm{R}}=$ The current resistance $(\mathrm{A})$

$\mathrm{I}_{\mathrm{c}}=$ The current capacitance $(\mathrm{A})$

Corresponding Author: Sahar R. Al-Sakini, Deptartment of Electromechanical Engineering, University of Technology, Ultimo, Australia 


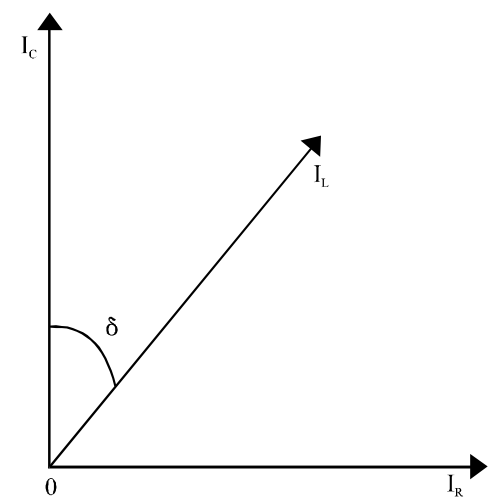

Fig. 1: Current resistance with current capacitance $(\tan \delta)$

$$
\tan \delta=\mathrm{I}_{\mathrm{R}} / \mathrm{I}_{\mathrm{C}}=(\mathrm{V} / \mathrm{R}) /\left(\mathrm{V}^{*} 2 \pi \mathrm{fC}\right)=1 /(2 \pi \mathrm{fRC})
$$

As it clear in Eq. 1 and 2, DDF or tan $\delta$ depends only on the Resistance (R), Capacitance (C) and frequency (f). These are changes when the temperature, frequency and voltage change. Index dielectric loss is another condition for dielectric losses which could be calculated as:

$$
\begin{gathered}
\mathrm{W}_{\mathrm{d}}=\sum_{\mathrm{ra}}{ }^{*} 2 \pi \mathrm{F}^{*} \mathrm{~V}_{\mathrm{rms}}^{2}{ }^{*} \mathrm{C}_{\mathrm{g}}{ }^{*} \tan \delta \\
\mathrm{V}_{\mathrm{rms} .}=\mathrm{V} / \sqrt{2} \\
\mathrm{C}_{\mathrm{g}}=10^{-9} / 18 \ln \left(\frac{\mathrm{r}_{\mathrm{ou}}}{\mathrm{r}_{\mathrm{in}}}\right)
\end{gathered}
$$

Where:

$\Sigma_{\text {ra }}=$ The losses factor for dielectric

$\mathrm{f}=$ The frequency $(\mathrm{Hz})$

$\mathrm{V}_{\mathrm{ms}}=$ The Voltage root mean square $(\mathrm{V})$

$\mathrm{V}=$ The peak value of Voltage $(\mathrm{V})$

$\mathrm{C}_{\mathrm{g}}=$ The cable Capacitance (Farad) with dielectric air or vacuum instead of material (dielectric) which represents insulation among the electrodes $(\mathrm{F} / \mathrm{m})$

$\mathrm{r}_{\mathrm{ou}}=$ The outer conductor radius ( $\mathrm{mm}$ )

$\mathrm{r}_{\text {in }}=$ The inner conductor radius $(\mathrm{mm})$ calculated $\left(\mathrm{W}_{\mathrm{d}}\right)$ by measuring the of conductor $\left(\mathrm{r}_{\text {ou, }}, \mathrm{r}_{\text {in }}\right) 50 \mathrm{~Hz}$ frequency and $\tan \delta$

Joint resistance: There are three type components of the contact Resistance $\left(\mathrm{R}_{\text {cot }}\right)$ metal Resistance $\left(\mathrm{R}_{\mathrm{m}}\right)$, Constriction Resistance $\left(\mathrm{R}_{\text {cons }}\right)$ and Oxidation Resistance (Roxid). When the lines current pass among a small area for the joint of cable the $\left(\mathrm{R}_{\text {cons }}\right)$ we find it.

When the surface smudge (oxidation), restricted between the joint members the roxid, we find it which is

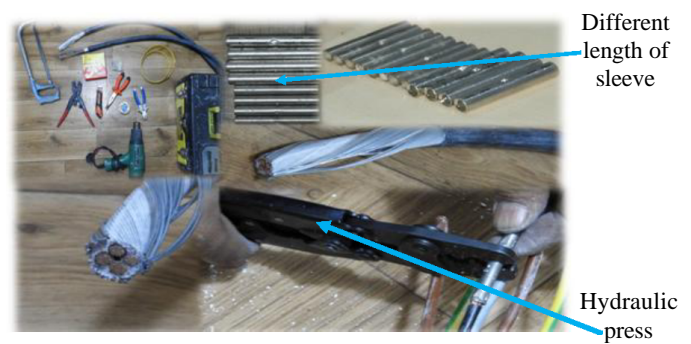

Fig. 2: Eexperimental tools

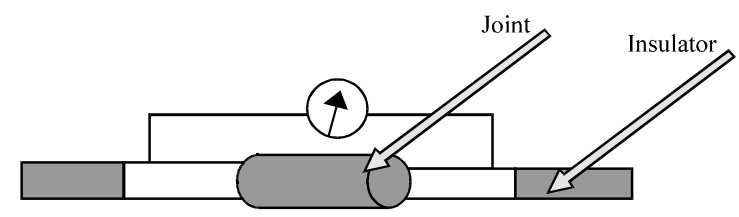

Fig. 3: Joint resistance measurement

directly affected by humidity, dust and temperature. The content occur at many points which it's called spots (Schoft et al., 2002):

$$
\begin{aligned}
& \mathrm{N}=2.5^{*} \mathrm{~F}_{\text {or }}^{0.2} \mathrm{~h}^{*} 10^{-5} \\
& \mathrm{~K}=\sqrt{\frac{\mathrm{F}_{\text {or }}}{3.1411^{*} \mathrm{~h}^{*} \mathrm{n}^{*} \eta}}
\end{aligned}
$$

Where:

$\mathrm{N}=$ The Number of spot

$\mathrm{K}=$ The radius spot $(\mathrm{cm})$

$\mathrm{F}_{\text {or }}=$ The contact load $(\mathrm{N})$

$\mathrm{h}=$ The break down point $\left(\mathrm{N} / \mathrm{m}^{2}\right)$

$\eta=$ The constant between 0.3-0.6

So, the contact resistance $\left(\mathrm{R}_{\mathrm{cot}}\right)$ :

$$
\mathrm{R}_{\mathrm{cot}}=\frac{\delta}{(\mathrm{K} * 3.141 * \mathrm{~N})}+\frac{\partial}{\mathrm{K}^{2} * 3.141 * \mathrm{~N}}
$$

Where:

$\delta=$ The resistivity of metal $(\mu \Omega \mathrm{cm})$

$\partial=$ The resistivity for the oxidation $(\mu \Omega \mathrm{cm})$

Experimentally work: The proper installation for the cables joint would be essential to obtain the results. All samples for test prepared by jointer experience from South Baghdad power plant. The connectors for examined were used with $\left(4^{*} 10\right) \mathrm{mm}^{2}, 3$-phase conductors. The sleeve (connectors) which used for this research have different length $(10,12,15) \mathrm{cm}$. As in Fig. 2 and 3, many samples were prepared by using the same cable size with different sleeve length at clean and dirt environment like dust and high humidity (oxidation). 


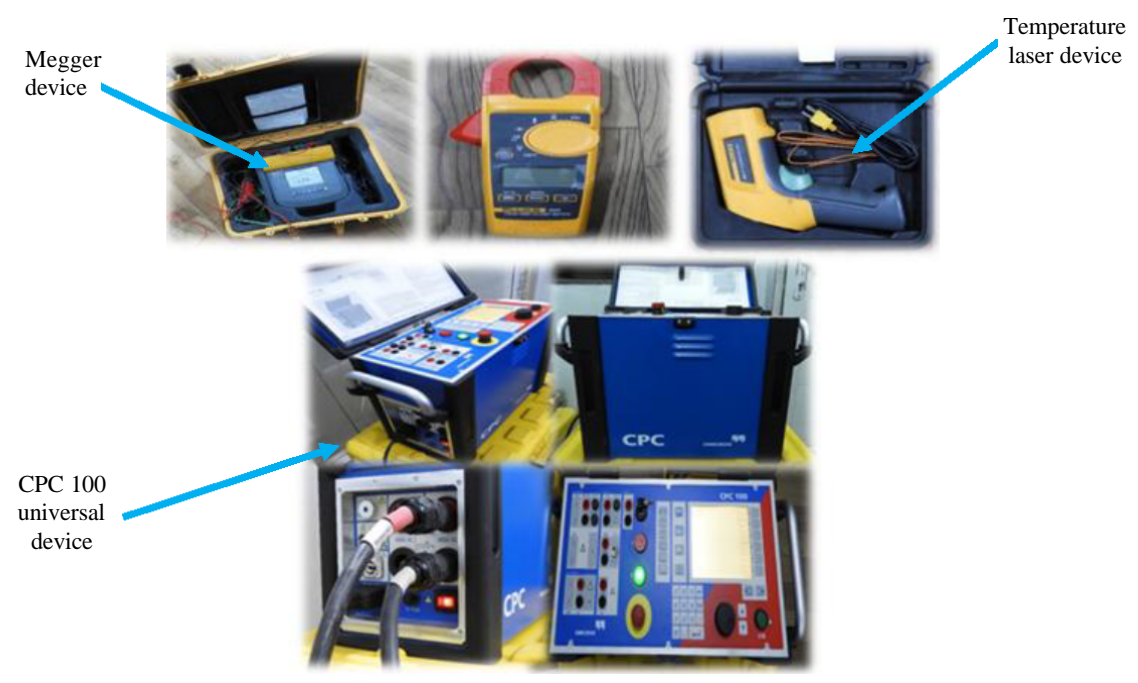

Fig. 4: Experimental devices

So, nine samples were prepared using the same cable by splicing cable which is easy conventional method. The samples for test were prepared by putting the sleeve at different conditions to form a compression joint by using a hydraulic press, this tool was used to reduce the resistance of joint by increasing pressure $\left(14 \mathrm{~N} / \mathrm{mm}^{2}\right)$, according to Eq. 9 as in Fig. 3 (Bhattacharyya et al., 2011):

$$
\mathrm{R}_{\text {cot }}=\mathrm{R}_{\mathrm{b}} / \mathrm{P}^{*} \mathrm{e}^{0.6}
$$

Where:

$\mathrm{P}=$ The pressure

$\mathrm{R}_{\mathrm{b}}=$ The resistance before pressure

The measurements for DDF $(\tan \delta)$ and losses index to these cases study are carried out at different temperature which resulted by following different current between 10-90 A with current steps of $20 \mathrm{~A}$, the current is measured by using clamp ammeter. The surface temperature for the joint of cable was measured when a current flows by using temperature laser tester.

The dissipation factor done by using CPC 100 universal testing device as show in Fig. 4 at room temperature, $76 \mathrm{~cm} \mathrm{Hg}$ pressure and $30 \%$ real humidity.

\section{RESULTS AND DISCUSSION}

The resistance of the joint connector is represents the contact between the sleeve and strand wires. Table 1 explains the joint resistance for cables with different length of sleeve $(10,12,15) \mathrm{cm}$ and resistance ratio (r) which represents the ratio of Resistance joint cable $\left(\mathrm{R}_{\mathrm{joi}}\right)$ to the resistance cable without joint $\left(\mathrm{R}_{\mathrm{cab}}\right)$ for the same length and at room temperature as Fig. 5 (Choudhnry et al., 2010):

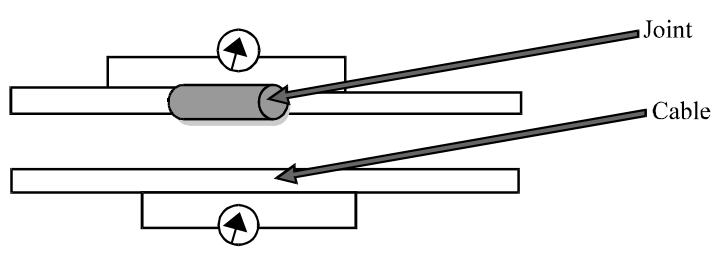

Fig. 5: Resistance measurement

$$
\mathrm{r}=\mathrm{R}_{\mathrm{joi}} / \mathrm{R}_{\mathrm{cab}}
$$

Table 1 indicates that unclean cables have a high joint resistance which causing heat in cable compared with clean cables because it is affected by particles of dust which causes bad contact in many point. So, a dust which covers a surface of cable must be prevented to make the best contact. Table 1 explain too the resistance ratio of humidity which causes oxidation. So, corrosion for the surface of conductor has been occurs. Therefore, increasing resistance joint which causes increase in resistance ratio that mean increase the temperature according to Eq. 11 (Cooley et al., 1983). So, the reliability is degraded and the performance is impaired:

$$
\mathrm{R}_{\text {joi. }}=\mathrm{R}_{\mathrm{O}}+\alpha\left(\mathrm{T}-\mathrm{T}_{\mathrm{o}}\right)
$$

Where:

$\mathrm{R}_{\mathrm{o}}=$ The Resistance cable at room Temperature $\mathrm{T}_{0}(\Omega)$

$\alpha=$ The coefficient for cooper

$\mathrm{T}=$ The new Temperature ${ }^{\circ} \mathrm{C}$

The parameters for dielectric measurements are carried out for different flow currents (10-90) steps (20 A) which causes rise in the surface temperate of joint cable. The results which obtained for cable with small joint 
Table 1: Cable resistance with resistance ratio ( $r$ ) with different lengths of sleeves

\begin{tabular}{|c|c|c|c|c|c|c|}
\hline \multirow{2}{*}{$\begin{array}{l}\text { Cable resistance } \\
\underline{\mathrm{R}}_{\mathrm{cab}}(\mathrm{m} \Omega)\end{array}$} & \multicolumn{2}{|c|}{ (r) for $10 \mathrm{~cm}$ sleeve length } & \multicolumn{2}{|c|}{ (r) for $12 \mathrm{~cm}$ sleeve length } & \multicolumn{2}{|c|}{ (r) for $15 \mathrm{~cm}$ sleeve length } \\
\hline & Clean & Unclean & Clean & Unclean & Clean & Uclean \\
\hline 42.5 & 1.317 & $\begin{array}{l}\text { Dust } 1.48 \\
\text { Oxidation }\end{array}$ & 1.322 & $\begin{array}{l}\text { Dust } 1.51 \\
\text { Oxidation }\end{array}$ & 1.38 & $\begin{array}{lr}\text { Dust } & 1.54 \\
\text { Oxidation } & 1.66\end{array}$ \\
\hline
\end{tabular}

Table 2: Different currents with data measured for small joint $(10 \mathrm{~cm})$

\begin{tabular}{llccc}
\hline $\mathrm{I}(\mathrm{A})$ & $\mathrm{T}\left({ }^{\circ} \mathrm{C}\right)$ & Tans $\delta^{*} 10^{3}$ & Losses index $* 10^{3}$ & $\mathrm{Cg}(\mathrm{Pf})$ \\
\hline 10 & 26.2 & 0.960 & 2.495 & 242.66 \\
30 & 40.9 & 0.930 & 2.481 & 242.64 \\
50 & 69.9 & 0.952 & 2.305 & 242.47 \\
70 & 76.0 & 1.015 & 2.150 & 242.34 \\
90 & 82.2 & 1.210 & 2.530 & 242.29 \\
\hline
\end{tabular}

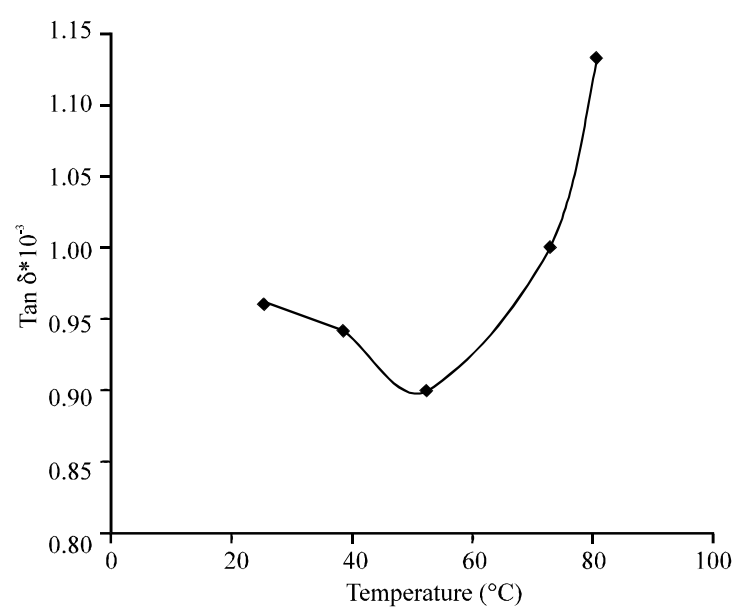

Fig. 6: Conductor temperature with tan $\delta$ for $15 \mathrm{~cm}$ long sleeve

$(10 \mathrm{~cm})$ are given in Table 2 . Table 3 obtained the results for cable with big joint $(15 \mathrm{~cm})$. The results for joint $(12 \mathrm{~cm})$ clear, there is no significant changes, so, it's neglected.

It's clear from the measured result in Table 2, the variation in current has a significant effect at the surface temperature for a joint cable, $\tan \delta$ a nd losses index.

As show in Fig. 6 that $\tan \delta$ is decrease from $25-51.2^{\circ} \mathrm{C}$ at this range tan $\delta$ about $\left(0.89^{*} 10^{-3}\right)$ and then began to increase by increasing the conductor temperature for long sleeve $(15 \mathrm{~cm})$ that explain the dielectric losses $(\tan \delta$ ) in conductor are decreased and the conductor insulation become more stable at $40-50^{\circ} \mathrm{C}$. For small sleeve as show in Fig. $7, \tan \delta$ more stable at $26.2-40.9^{\circ} \mathrm{C}$ about $0.93^{*} 10^{-3}$ and then began to increase.

Figure 8 and 9 explain the relationship between the temperature and the losses index at the insulation materials which are decreases from $20^{\circ} \mathrm{C}$ up to $60^{\circ} \mathrm{C}$ for $15 \mathrm{~cm}$ sleeve and from $20^{\circ} \mathrm{C}$ up to $40^{\circ} \mathrm{C}$ for $10 \mathrm{~cm}$ sleeve. Then, up to 78.8 and $82.2^{\circ} \mathrm{C}$ for 15 and $10 \mathrm{~cm}$ sleeve,
Table 3: Different currents with data measured for big joint $(15 \mathrm{~cm})$

\begin{tabular}{llccc}
\hline $\mathrm{I}(\mathrm{A})$ & $\mathrm{T}\left({ }^{\circ} \mathrm{C}\right)$ & Tans $\delta * 10^{3}$ & Losses index $* 10^{3}$ & $\mathrm{Cg}(\mathrm{Pf})$ \\
\hline 10 & 25 & 0.961 & 2.48 & 242.63 \\
30 & 37.8 & 0.941 & 2.3 & 242.61 \\
50 & 51.2 & 0.899 & 2.5 & 242.54 \\
70 & 71.2 & 1 & 2.58 & 242.29 \\
90 & 78.8 & 1.132 & 2.67 & 242.27 \\
\hline
\end{tabular}

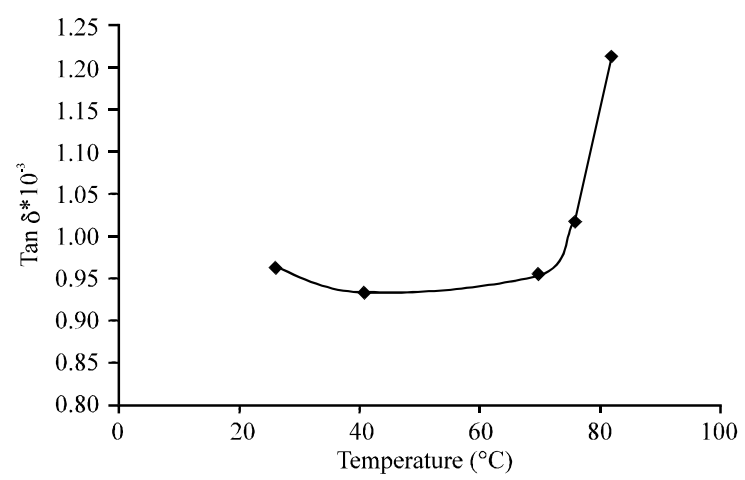

Fig. 7: Conductor temperature with tan $\delta$ for $10 \mathrm{~cm}$ long sleeve

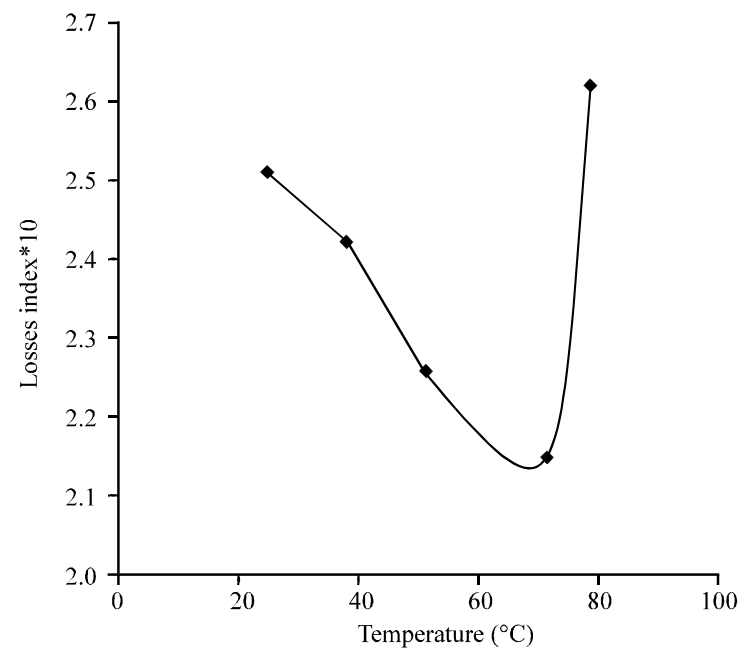

Fig. 8: Conductor temperature with losses index for $15 \mathrm{~cm}$ long sleeve

respectively. At higher temperature, the dielectric losses crumble the insulation further. These Fig. 8 explain the same behavior with Fig. 9 of $\tan \delta$.

Figure 10 and 11 , explain the relation between the capacitance of dielectric insulation for conductor and conductor temperature. The magnitude of the capacitance 


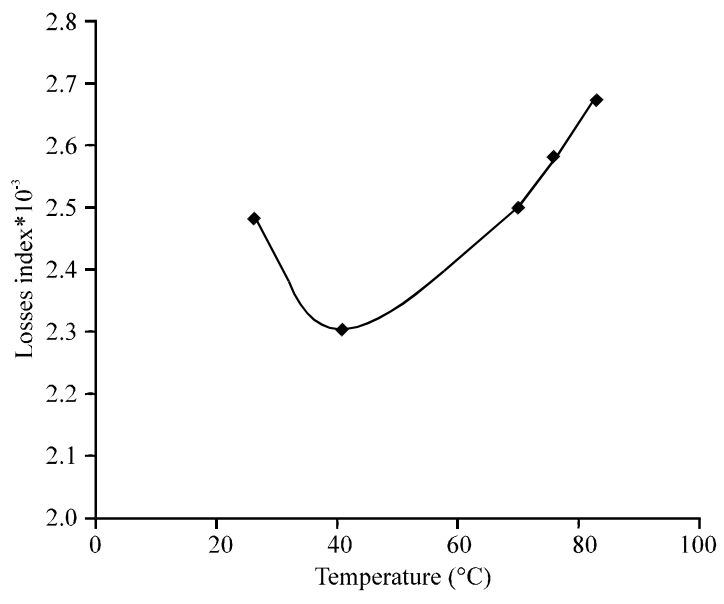

Fig. 9: Conductor temperature with losses index for $10 \mathrm{~cm}$ long sleeve

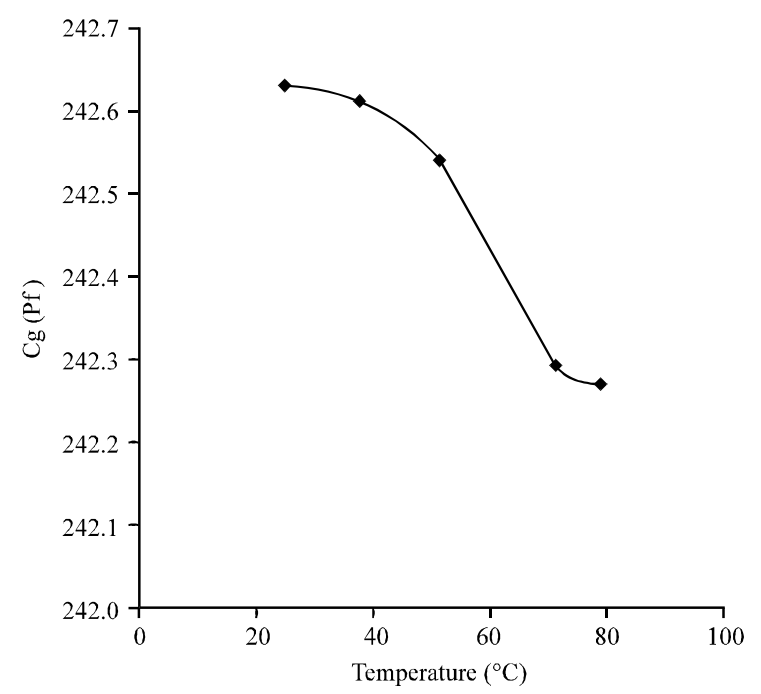

Fig. 10: Conductor temperature with capacitance for $15 \mathrm{~cm}$ long sleeve

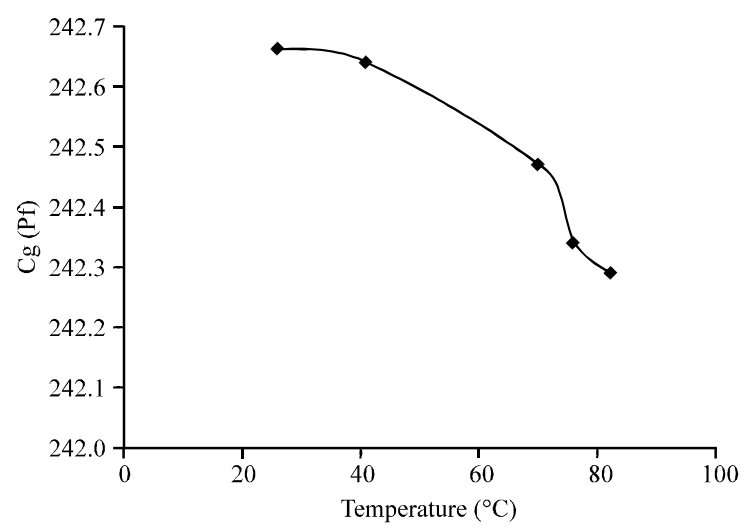

Fig. 11: Conductor temperature with capacitance for $10 \mathrm{~cm}$ long sleeve is lightly decreased when the conductor temperatures increased from $25-78.8^{\circ} \mathrm{C}$ and from $26.2-82.2^{\circ} \mathrm{C}$ for 15 and $10 \mathrm{~cm}$ length of sleeve, respectively. While the capacitance is decreasing from 242.63-242.27 Pf and from 242.66-242.29 Pf for 15 and $10 \mathrm{~cm}$ length of sleeve, respectively.

\section{CONCLUSION}

In this study, the efficient performance of contact cable joint is dependent on maintaining as possible low resistance. Low resistance at the conductive joint can be done by cleaning or smoothing the surface cable, so, we can get a small resistance at the joint cable.

The humidity of the environment influence on the surface of the joint cable too which causes the oxidation on the surface for joint cable. Therefore, we can get a small resistance at the joint cable by buffing or cleaning the surface cable.

\section{SUGGESTIONS}

To improve best performance for the joint cable, increase the length of joint cable because the increase in length joint lead to increase the contact area which causes more increase at heat transfer to the environment but it was saw that the increase the joint length more than limit has not affect significantly in the performance of the joint.

The results explained that changes in temperature for a dielectric insulation are affect for the quality of the insulation cable. After 30 and $50^{\circ} \mathrm{C}$ the tan delta and dielectric index losses are increasing rapidly for long sleeve $(15 \mathrm{~cm})$ and short sleeve $12 \mathrm{~cm}$, respectively.

The higher temperature joint cable causes increased the dielectric losses which may causes breakdown and early ageing in conductor cable.

\section{REFERENCES}

Bhattacharyya, S., A. Choudhury, H.R. Jariwala, M.S. Shetty and R. Kumar, 2011. Electrical performance of conductive bolted connections of copper and Aluminum busbars. Intl. J. Engg. Techsci., 2: 275-280.

Braunovic, M., 1994. Aluminium connections: Legacies of the past. Proceedings of the 1994 International IEEE Holm Conference on Electrical Contracts, October 17-19, 1994, IEEE, Chicago, Illinois, USA., pp: 1-31. 
Choudhnry, A. H. Jariwala and S. Bhaltacharya, 2010. High quality joints of copper bus bars. Intl. J. Eng. Sci. Technol., 2: 3808-3815.

Cooley, W.L., R.L. McConnell and H.W. Hill, 1983. Use of cable surface temperature to detect high-resistance splices. IEEE. Trans. Ind. Appl., 19: 434-439.

Otowski, W., R. Courteau, T.K. Bose and L. Lamarre, 1993. Effect of temperature and time on the dissipation factor of power cable junctions. Proceedings of IEEE 1993 International Conference on Electrical Insulation and Dielectric Phenomena-(CEIDP'93), October 17-20, 1993, IEEE, Pocono Manor, Pennsylvania, USA., pp: 763-768.

Sarathi, R., S. Das, C. Venkataseshaiah and N. Yoshimura, 2003. Investigations of growth of electrical trees in XLPE cable insulation under different voltage profiles. Proceedings of the 2003 Annual Report Conference on Electrical Insulation and Dielectric Phenomena, October 19-22, 2003, IEEE, Albuquerque, New Mexico, USA., pp: 666-669.
Schoft, S., J. Kindersberger and H. Lobl, 2002. Joint resistance of busbar-joints with randomly rough surfaces. Proceedings of the 21th International Conference on Electrical Contacts, September 9-12, 2002, Zurich, Switzerland, pp: 230-237.

Wang, Y., J. Zhao and F. Lu, 2009. Test research of environment influence to $\tan \mathrm{d}$ of capacitive equipment. Proceedings of the 2009 IEEE 9th International Conference on the Properties and Applications of Dielectric Materials, July 19-23, 2009, IEEE, Harbin, China, ISBN:978-1-4244-4367-3, pp: 366-369.

Werelius, P., M. Ohlen, J. Cheng and D.M. Robalino, 2012. Dielectric frequency response measurements and dissipation factor temperature dependence. Proceedings of the 2012 IEEE International Symposium on Electrical Insulation, June 10-13, 2012, IEEE, San Juan, Puerto Rico, USA., ISBN:978-1-4673-0488-7, pp: 296-300.

Zhang, J.G. and X.M. Wen, 1986. The effect of dust contamination on electric contacts. IEEE. Trans. Compon. Hybrids Manuf. Technol., 9: 53-58. 